\title{
Charge Transfer and Diffusion at Perovskite/PCBM Interface Probed by Transient
} Absorption and Reflection

Meng Zhou, ${ }^{\dagger}$ Julio S. Sarmiento, ${ }^{\dagger}$ Chengbin Fei, He Wang*

Department of Physics, University of Miami, Coral Gables, Florida 33146, United States

*To whom correspondence should be addressed: Email: hewang@miami.edu

${ }^{\dagger}$ These authors contributed equally

Table of Contents

1. Absorption of the film versus thickness.

2. TR measurements on multiple $1 \mathrm{M}$ films.

3. TA and TR measurements with 600 and $710 \mathrm{~nm}$ excitation.

4. Temperature dependent TA measurements.

5. Temperature dependent TR measurements.

6. Comparison of TA and TR dynamics of $0.25 \mathrm{M}$ film.

7. TA and TR measurements on $0.75 \mathrm{M}$ films.

8. Comparison of TR dynamics with front and back excitation.

9. Simulation of carrier density.

10. Film thickness measurements. 


\section{Absorption of the film versus thickness.}

According to Beer Lambert law, the intensity of an incident light in a continuous material can be written as:

$$
I=I_{0} e^{-\alpha x}
$$

where $I$ is the light intensity at a specific depth $x, I_{0}$ is the incident light intensity before reaching the sample, $\alpha$ is the absorption coefficient. From the UV-vis absorption spectra, it is possible to obtain $\alpha$. The penetration depth $\sigma$ is the depth where $I$ reach $1 / \mathrm{e}$ of $I_{0}$ and $\sigma=1 / \alpha$. In $1 \mathrm{M}$ film and $0.25 \mathrm{M}$, the penetration depth for $400 \mathrm{~nm}$ is calculated to be $32 \mathrm{~nm}$. In $1 \mathrm{M}$ film, the penetration depth for $700 \mathrm{~nm}$ is calculated to be $240 \mathrm{~nm}$.
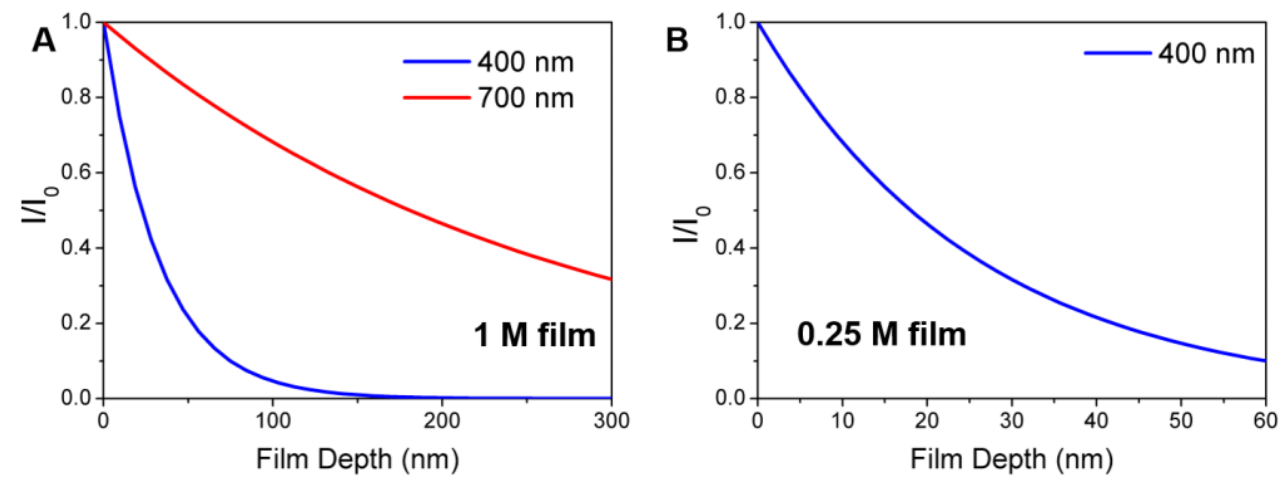

Figure S1. Probe light intensity as a function of film depth for (A) $1 \mathrm{M}$ film and (B) $0.25 \mathrm{M}$ film. 


\section{TR measurements on multiple $1 \mathrm{M}$ films.}
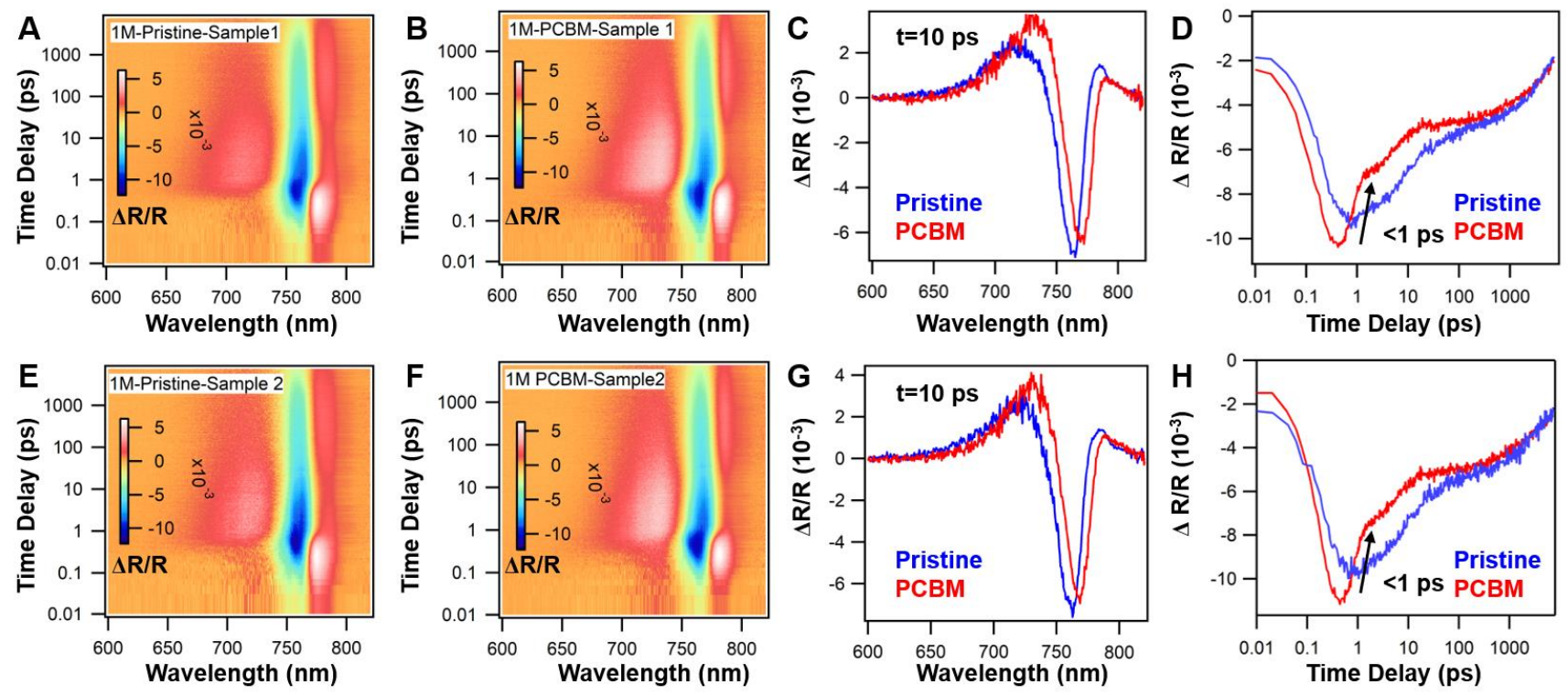

Figure S2. TR measurements on multiple 1M films. (A-D) TR data map, TR spectra at $10 \mathrm{ps}$ and kinetic decays of sample 1; (E-F) TR data map, TR spectra at $10 \mathrm{ps}$ and kinetic decays of sample 2. An ultrafast decay can be observed in both PCBM coated films.
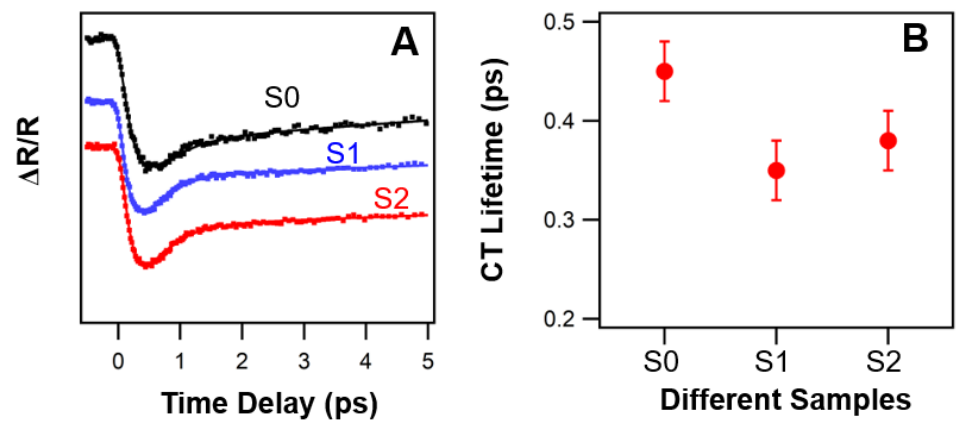

Figure S3. Comparison of early carrier dynamics of multiple samples. (A) TR kinetics of multiple samples, S0 represents the sample used in the main text, S1 and S2 represent sample 1 and sample 2 in Figure S2 respectively; (B) CT lifetime obtained from multi-exponential decay. 

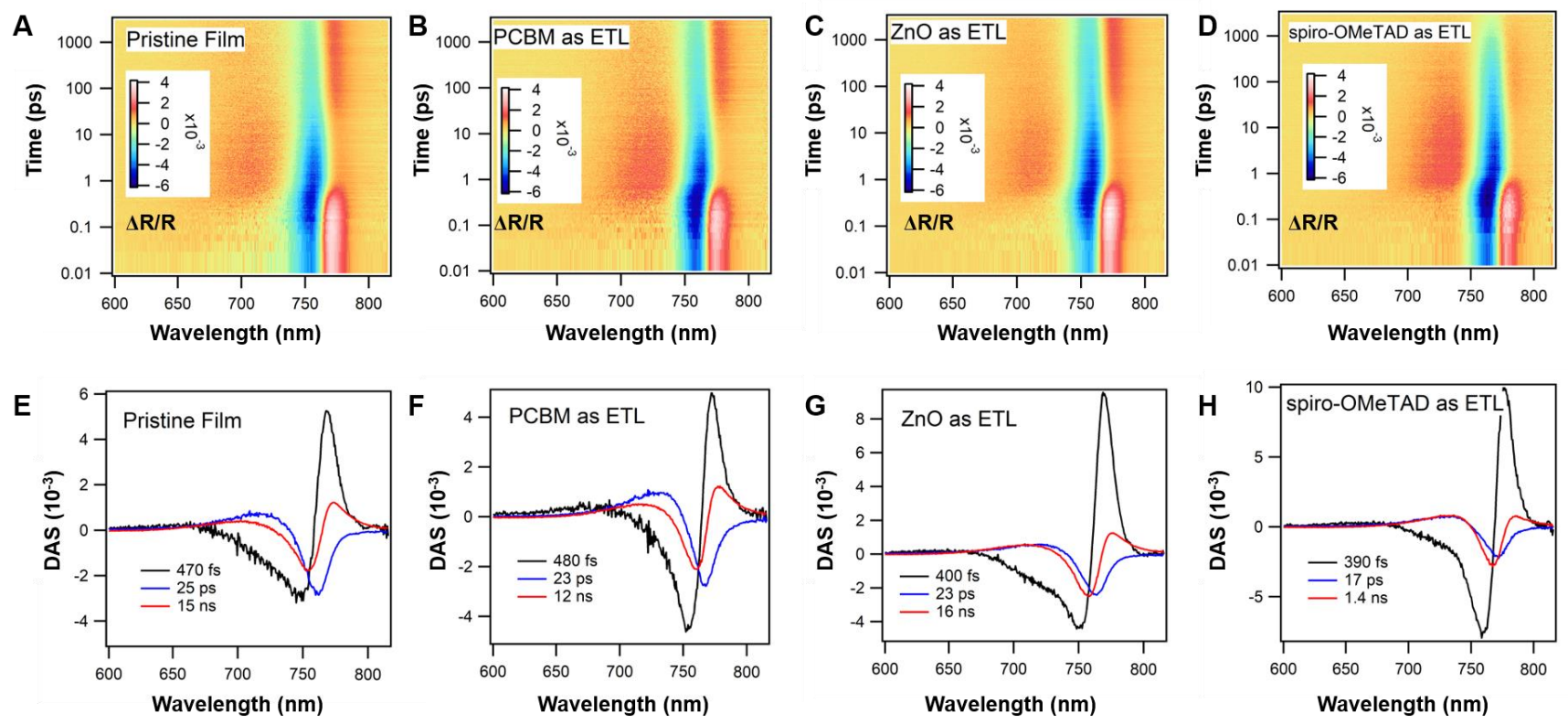

Figure S4. Carrier dynamics and global fitting on $\mathrm{MAPbI}_{3}$ coated with different ETL and HTL. Transient reflection data map of (A) $\mathrm{MAPbI}_{3}$ film, (B) $\mathrm{MAPbI}_{3}: \mathrm{PCBM}$ film, (C) $\mathrm{MAPbI}_{3}: \mathrm{ZnO}$ film and (D) MAPbI3:spiro-OMeTAD film. Decay associated spectra (DAS) obtained from global fitting on the TR data of (E) $\mathrm{MAPbI}_{3}$ film, (F) MAPbI 3 :PCBM film, (G) MAPbI $3: \mathrm{ZnO}$ film and (H) MAPbI3:spiro-OMeTAD film. 
3. TA and TR measurements with $600 \mathrm{~nm}$ and $710 \mathrm{~nm}$ excitation.
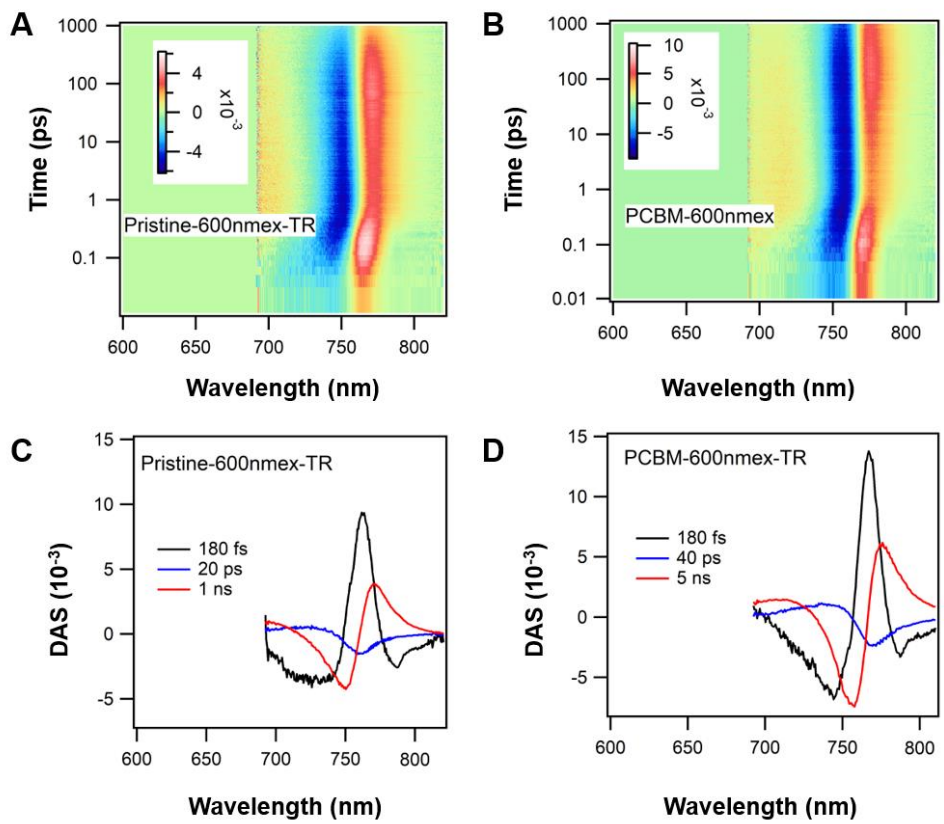

Figure S5. TR of $\mathrm{MAPbI}_{3}$ and $\mathrm{MAPbI}_{3} / \mathrm{PCBM}$ films with $600 \mathrm{~nm}$ excitation. TR data map of (A) $\mathrm{MAPbI}_{3}$ film and (B) $\mathrm{MAPbI}_{3} / \mathrm{PCBM}$ film. Decay associated spectra (DAS) obtained from global fitting on TR of (C) $\mathrm{MAPbI}_{3}$ and (D) $\mathrm{MAPbI}_{3} / \mathrm{PCBM}$ film.
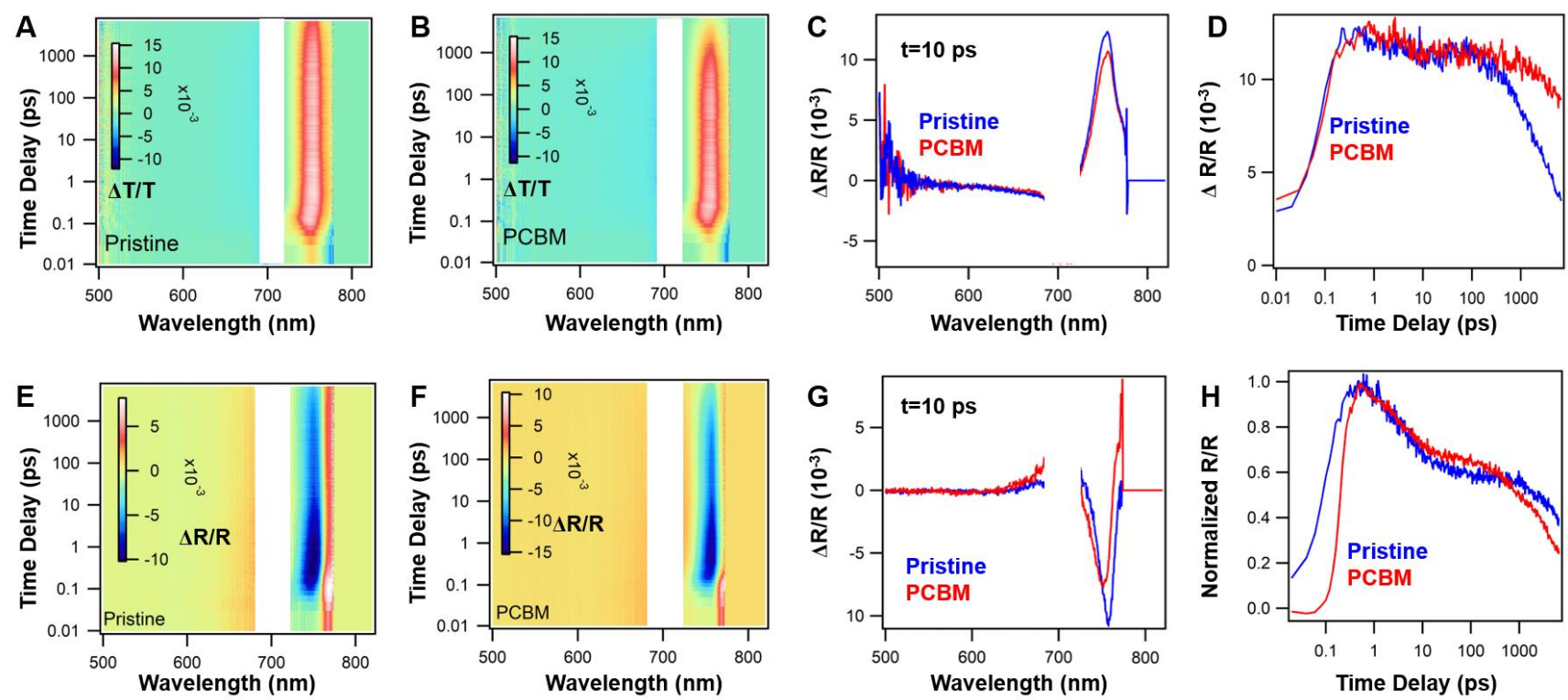

Figure S6. TA and $\mathrm{TR}$ of $\mathrm{MAPbI}_{3}$ and $\mathrm{MAPbI}_{3} / \mathrm{PCBM}$ films with $710 \mathrm{~nm}$ excitation. (A-B) TA data map of pristine film and film coated with PCBM; (C) TA spectra of two films probed at $10 \mathrm{ps;}$ (D) TA kinetics of two films probed at GSB maxima. (E-F) TR data map of pristine film and film coated with PCBM; (G) TR spectra of two films probed at $10 \mathrm{ps}$; (H) TR kinetics of two films probed at GSB maxima. The spikes around $700 \mathrm{~nm}$ due to laser scattering have been cut off for clarity. 


\section{Temperature dependent TA measurements.}
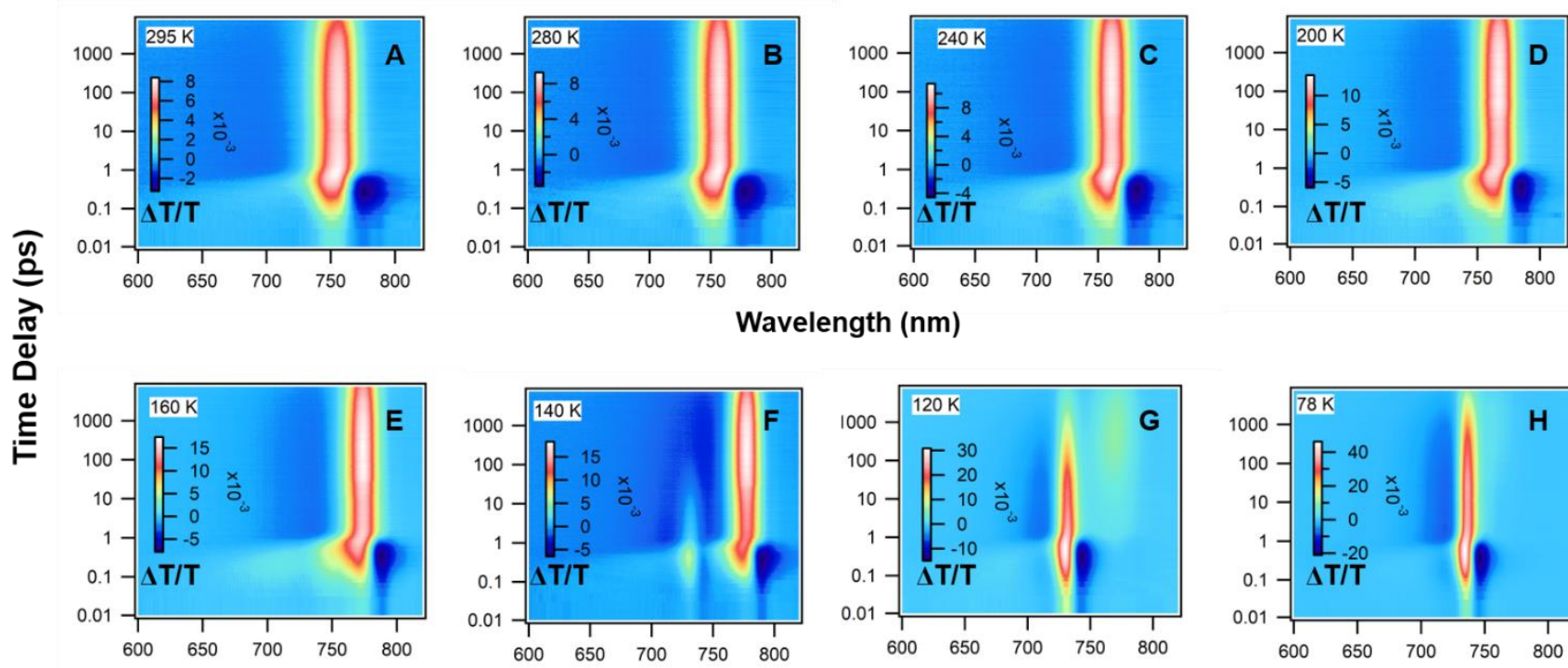

\section{Wavelength $(\mathrm{nm})$}
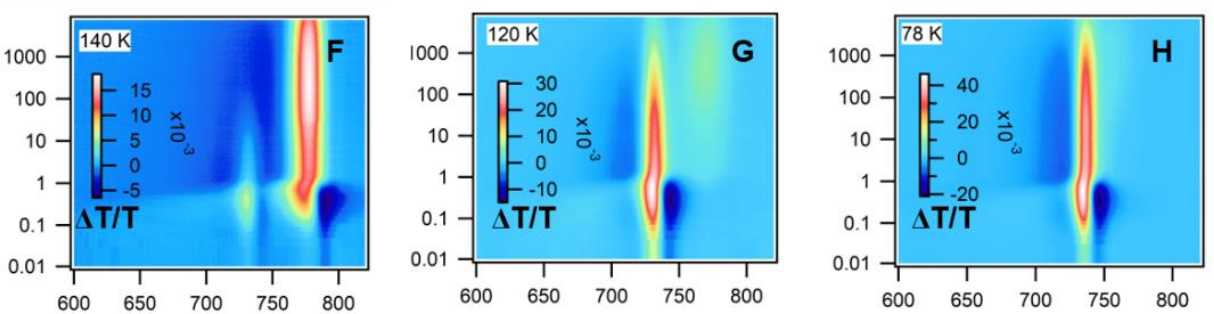

Wavelength $(\mathrm{nm})$

Figure S7. TA data map of pristine film with $400 \mathrm{~nm}$ excitation at different temperatures.
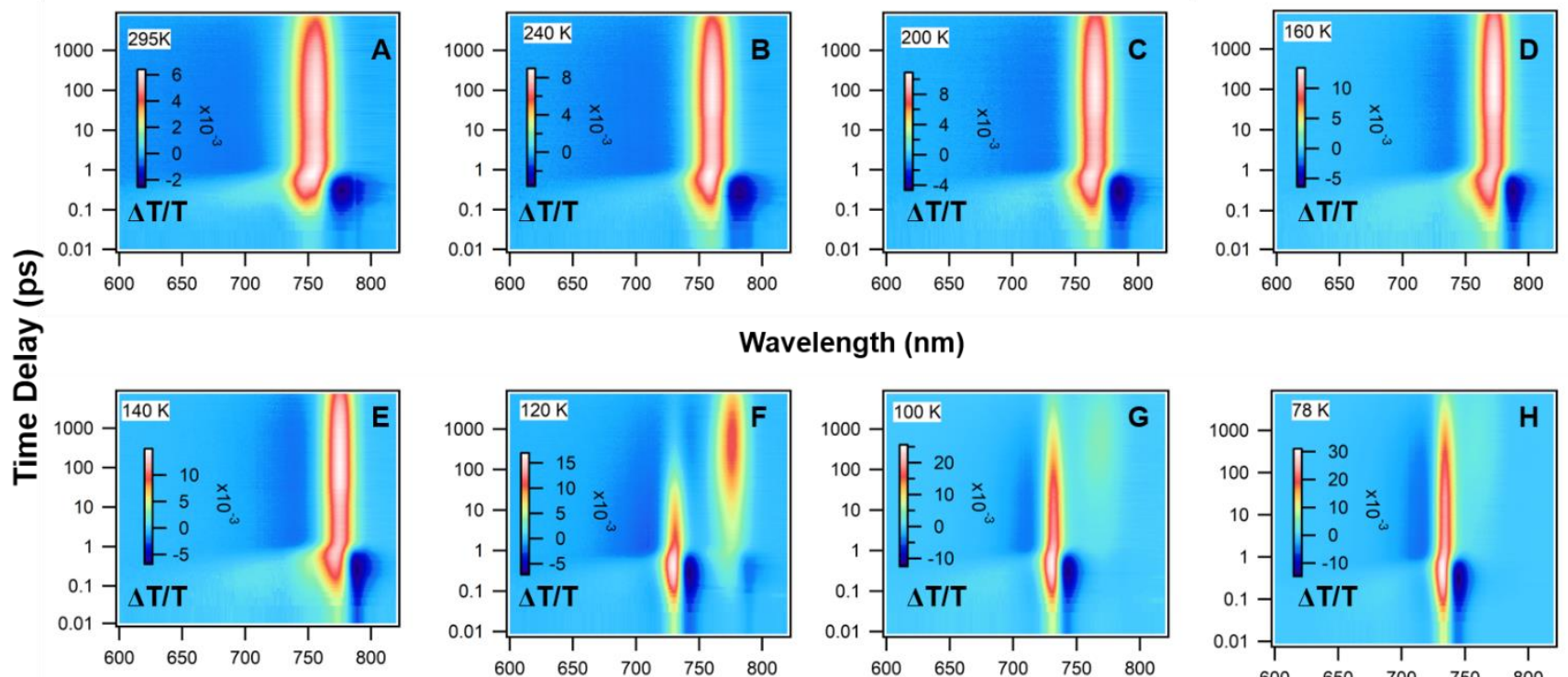

\section{Wavelength (nm)}
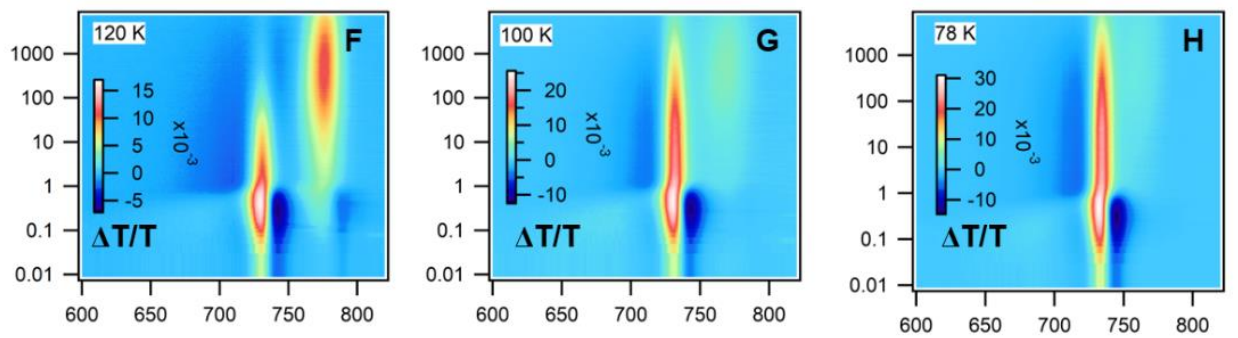

Wavelength $(\mathrm{nm})$

Figure S8. TA data map of film coated with PCBM with $400 \mathrm{~nm}$ excitation at different temperatures. 


\section{Temperature dependent TR measurements.}
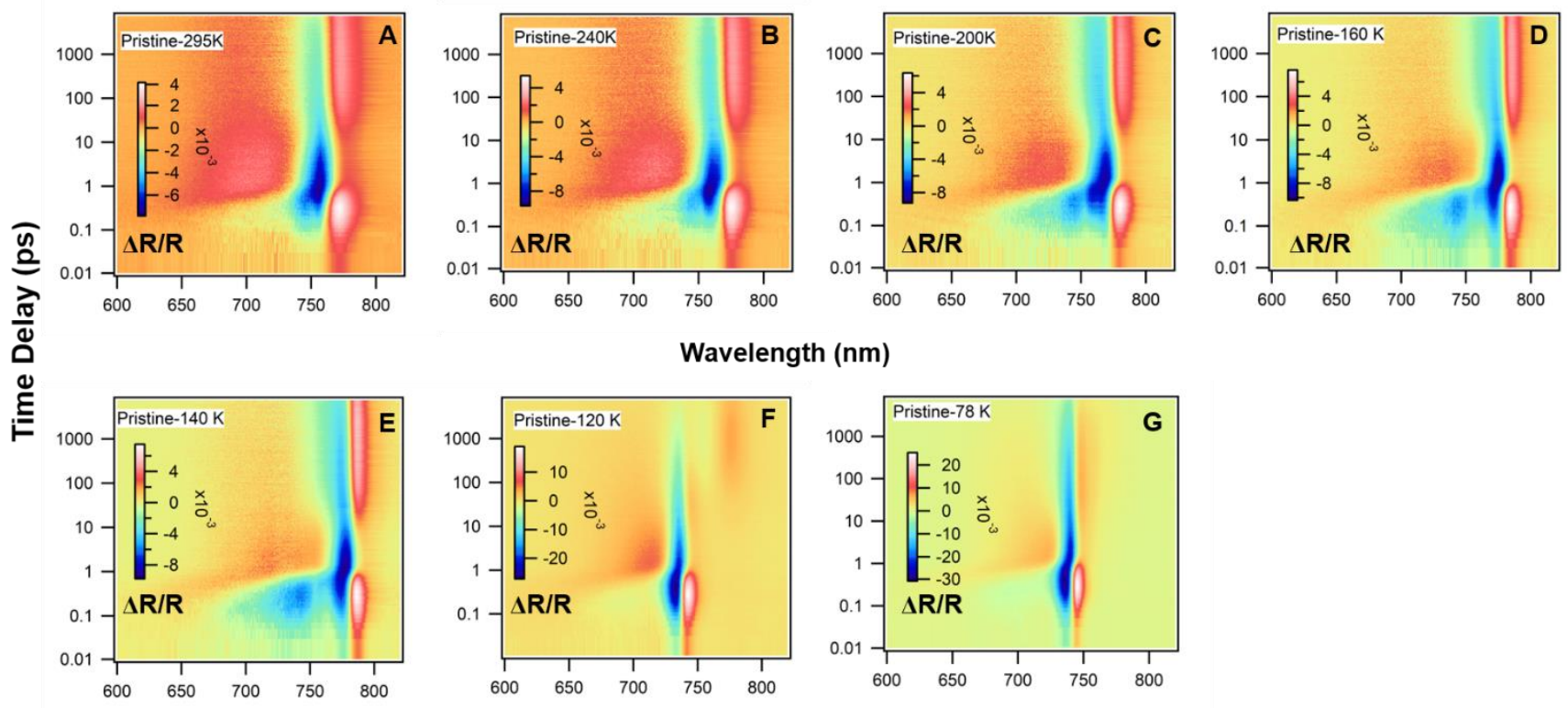

Wavelength (nm)
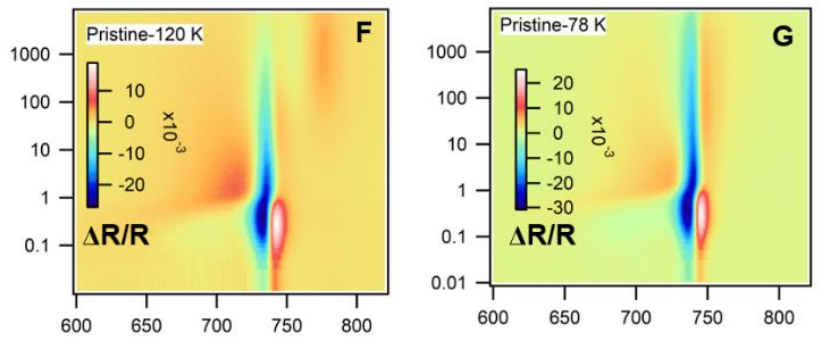

Wavelength (nm)

Figure S9. TR data map of pristine film with $400 \mathrm{~nm}$ excitation at different temperatures.
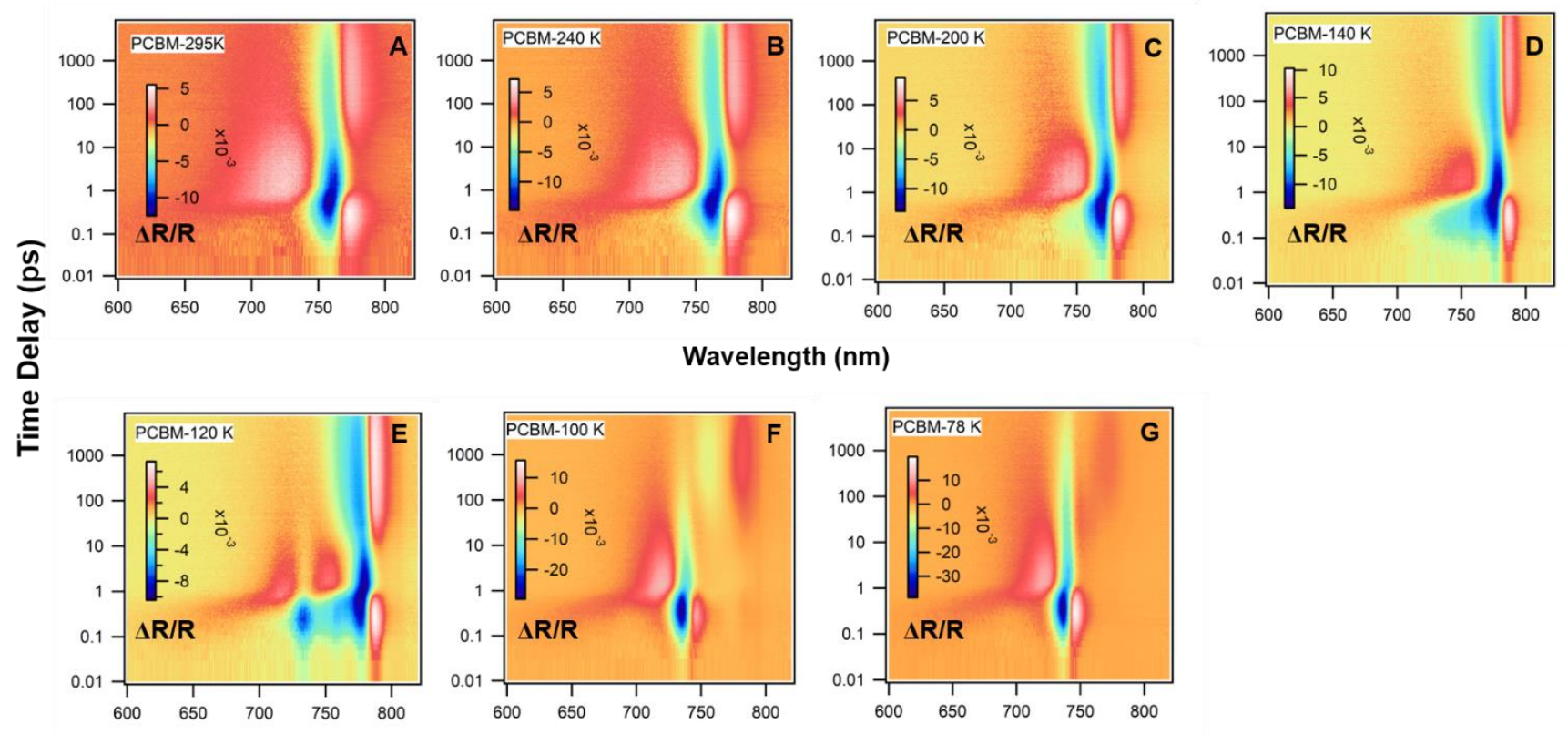

Wavelength $(\mathrm{nm})$
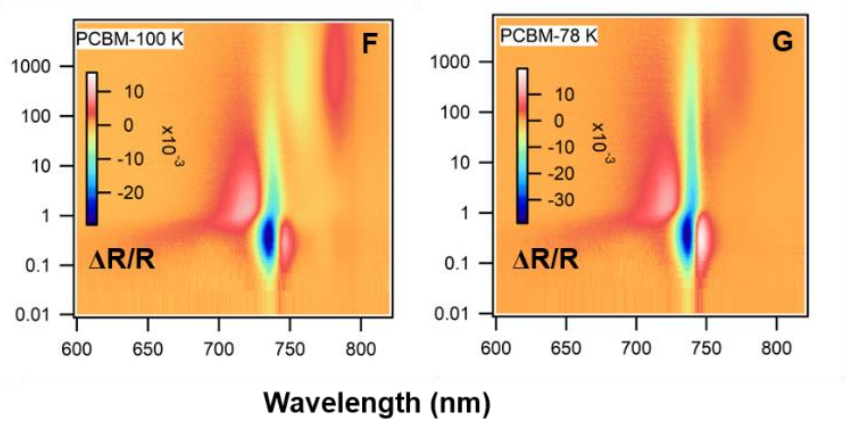

Figure S10. TR data map of film coated with PCBM with $400 \mathrm{~nm}$ excitation at different temperatures. 


\section{Comparison of TA and TR dynamics of $0.25 \mathrm{M}$ film.}

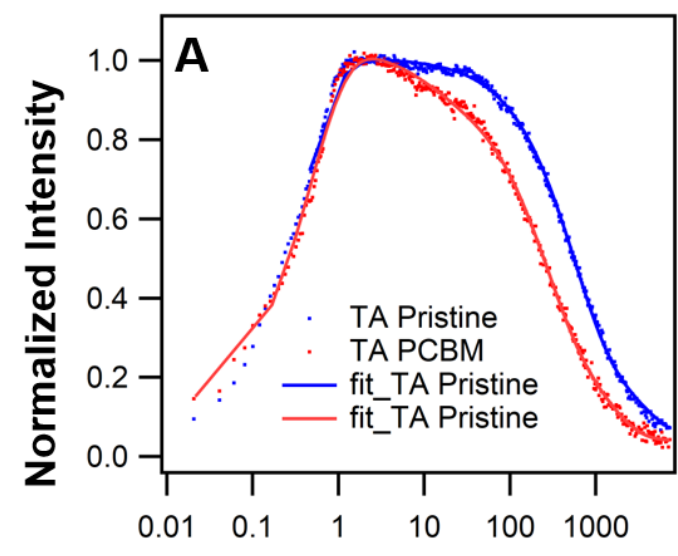

Time Delay (ps)

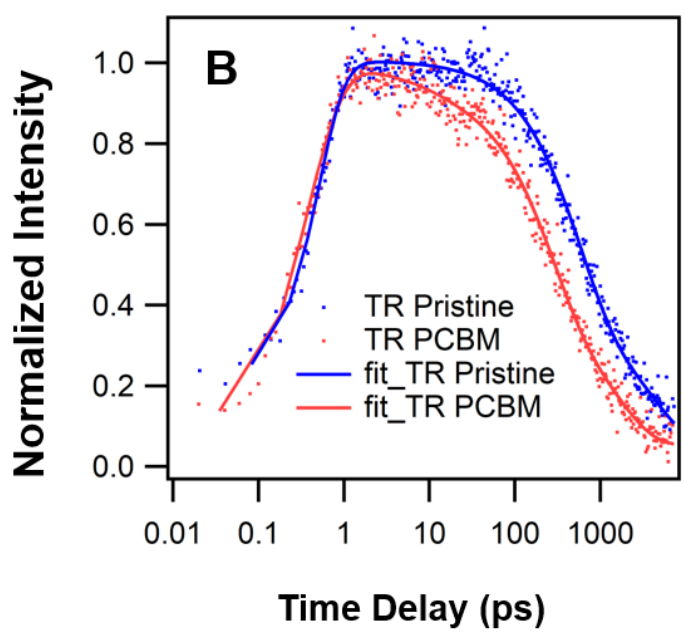

Figure S11. (A) TA dynamics and fitting of pristine film and film coated with PCBM; (B) TR dynamics and fitting of pristine film and film coated with PCBM. In both cases, an additional 11 ps process can be observed in film coated with PCBM.
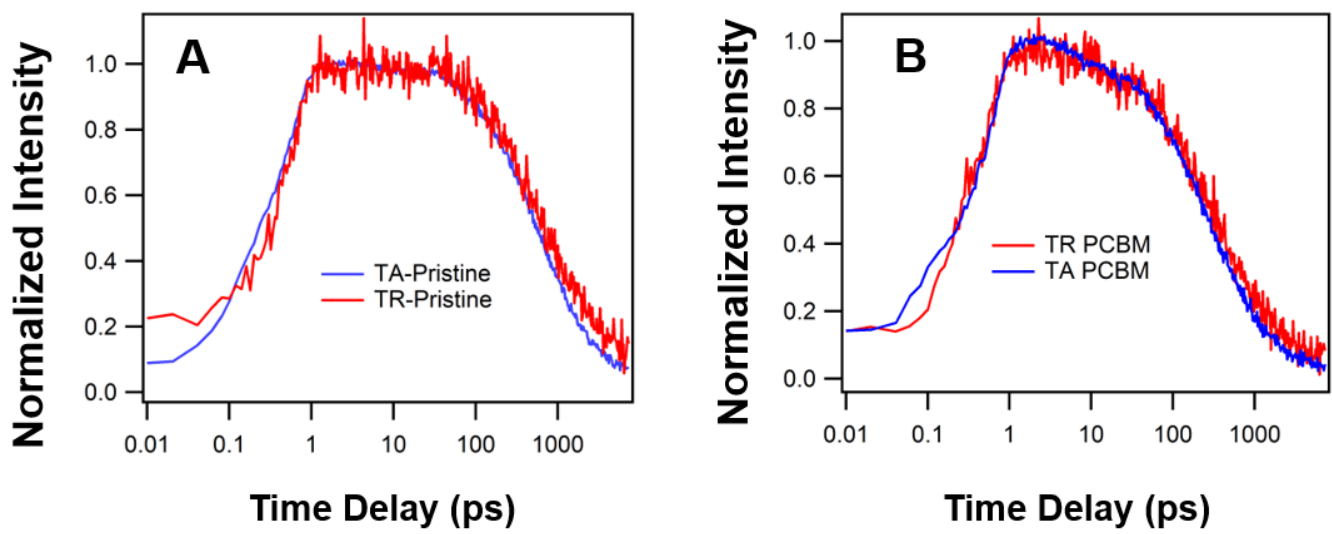

Figure S12. (A) Comparison between TA and TR kinetics of pristine films; (B) comparison between TA and TR kinetics of films coated with PCBM. 


\section{TA and TR measurements on $0.75 \mathrm{M}$ films.}

We repeated the experiment in film prepared from $0.75 \mathrm{M}$ solution. It is found that the photophysical behavior of $0.75 \mathrm{M}$ is similar to that of $0.25 \mathrm{M}$ film. After PCBM is spincoated onto the $0.75 \mathrm{M}$ film, there is an additional decay component showing in TR spectra which should originate from CT.
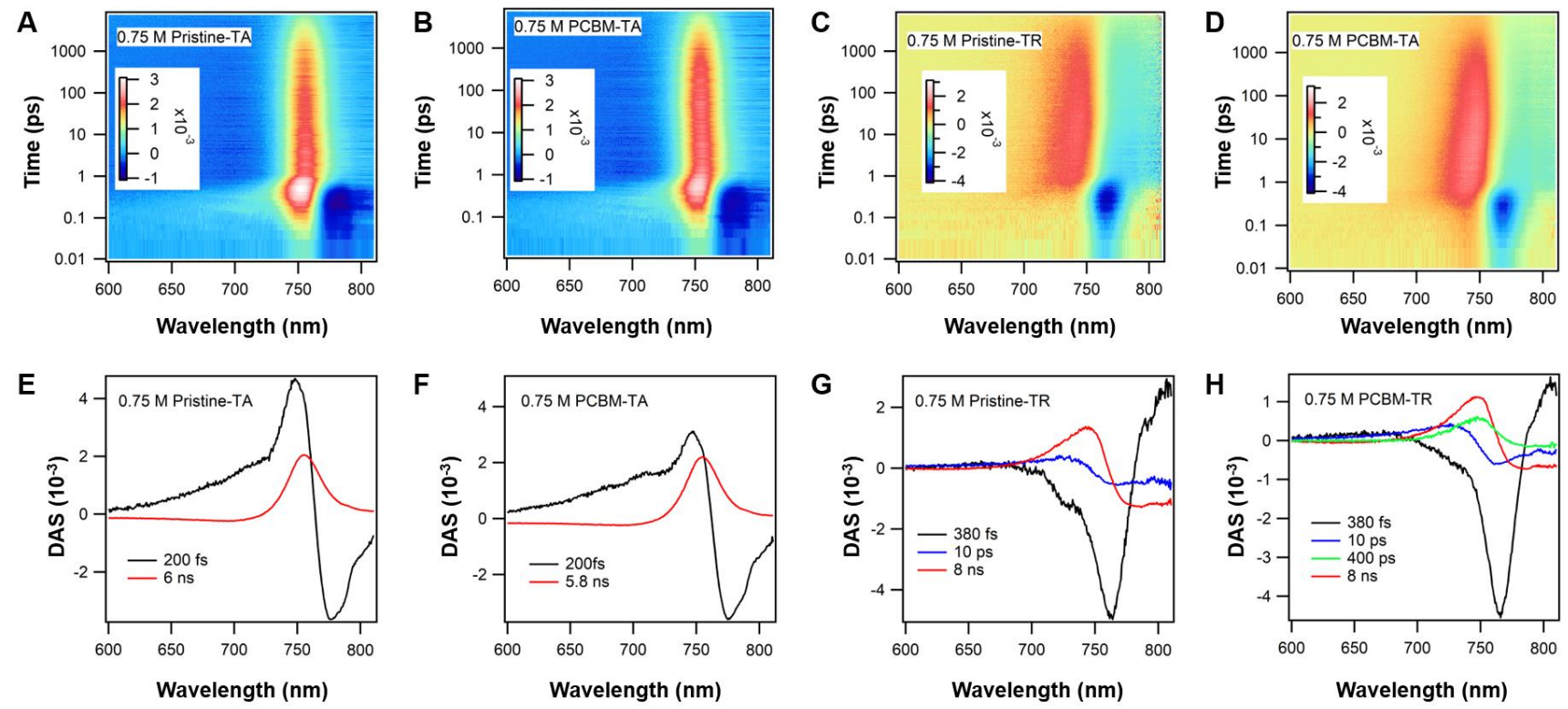

Figure S13. Carrier dynamics and global fitting on $\mathrm{MAPbI}_{3}$ and $\mathrm{MAPbI}_{3}: \mathrm{PCBM}$ films prepared from $0.75 \mathrm{M}$ solution with $400 \mathrm{~nm}$ excitation. (A) TA data map of $\mathrm{MAPbI}_{3}$; (B) TA data map of $\mathrm{MAPbI}_{3}: \mathrm{PCBM}$; (C) TR data map of $\mathrm{MAPbI}_{3}$; (D) TR data map of $\mathrm{MAPbI}_{3}: \mathrm{PCBM}$. Decay associated spectra (DAS) obtained from global fitting on (E) TA of $\mathrm{MAPbI}_{3}$; (F) TA of $\mathrm{MAPbI}_{3}: \mathrm{PCBM}$; (G) TR of $\mathrm{MAPbI}_{3}$ and (H) TR of MAPbI$: \mathrm{PCBM}$ 
8. Comparison of TR dynamics with front and back excitation.
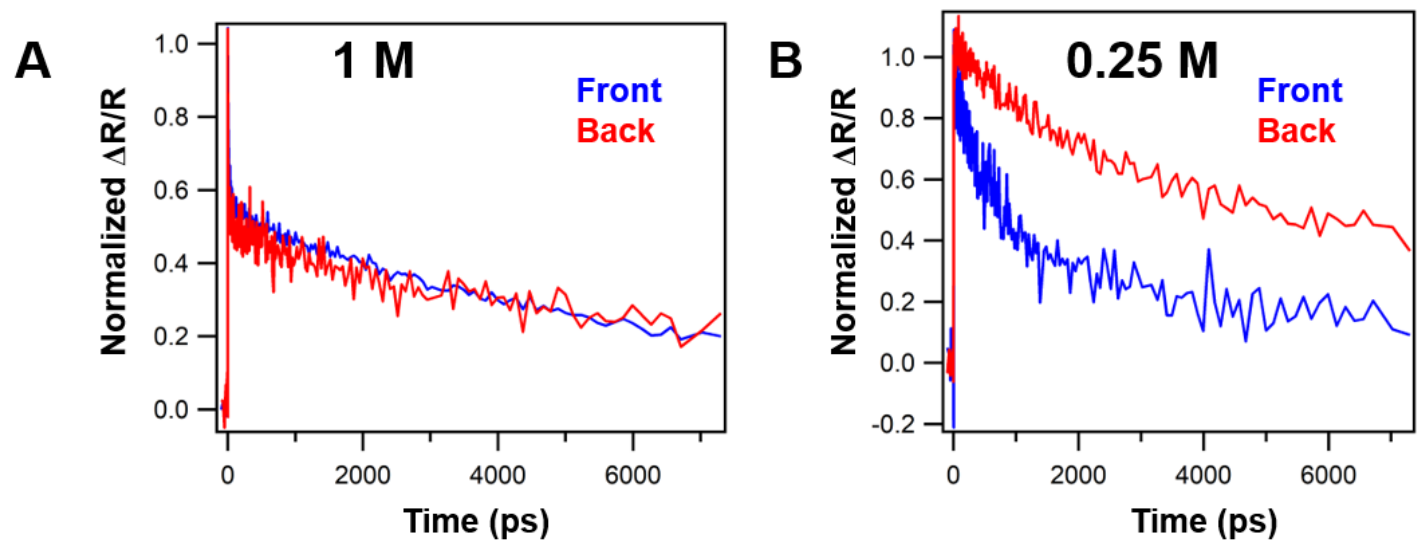

Figure S14. (A) TR dynamics of $1 \mathrm{M}$ film with front and back excitations; (B) TR dynamics of $0.25 \mathrm{M}$ film with front and back excitations;

9. Simulation of carrier density.
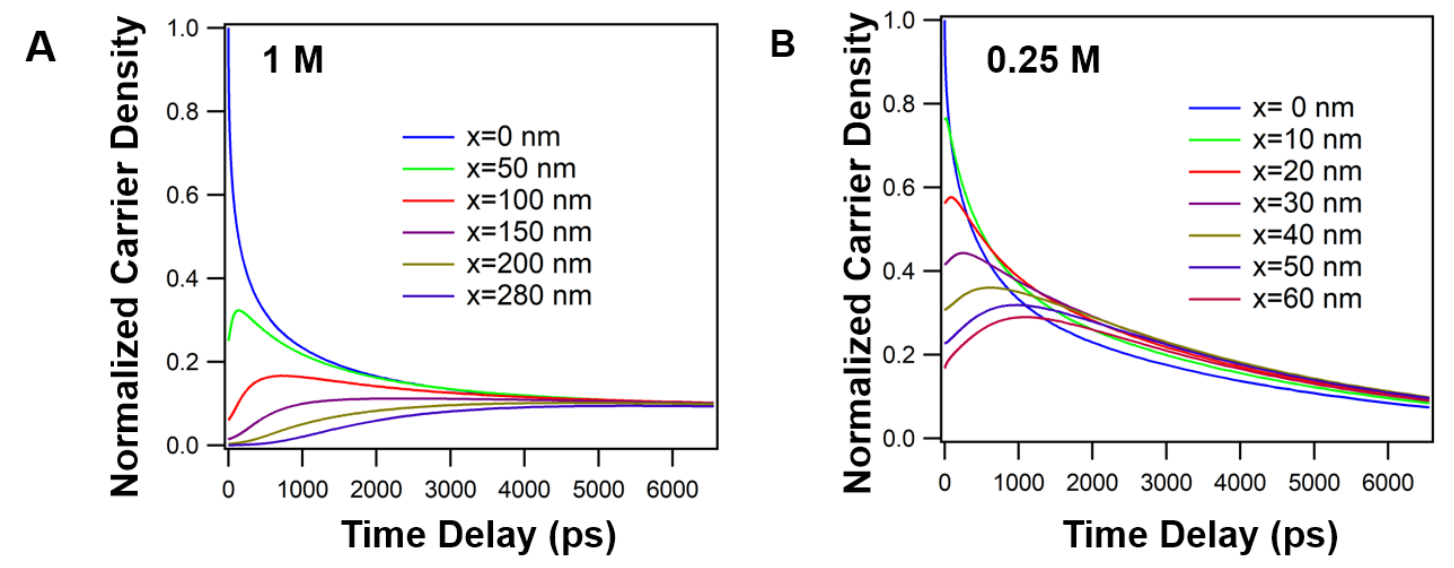

Figure S15. Normalized carrier density as a function of time at different depths of (C) $1 \mathrm{M}$ film and (B) $0.25 \mathrm{M}$ film.

\section{Film thickness measurements.}

Table S1. Thickness of all films measured by profilometer.

\begin{tabular}{|l|l|l|l|}
\hline Type/Concentration & $1 \mathrm{M}$ & $0.75 \mathrm{M}$ & $0.25 \mathrm{M}$ \\
\hline Pristine & $280 \mathrm{~nm}$ & $190 \mathrm{~nm}$ & $60 \mathrm{~nm}$ \\
\hline PCBM as ETL & $300 \mathrm{~nm}$ & $205 \mathrm{~nm}$ & $75 \mathrm{~nm}$ \\
\hline ZnO as ETL & $290 \mathrm{~nm}$ & & \\
\hline Spiro as HTL & $310 \mathrm{~nm}$ & & \\
\hline
\end{tabular}

